\title{
Experimental Evaluation of the True Remaining Capacity of Legacy Lead-Acid Batteries
}

\author{
Khadim Ullah Jan \\ Université Paris-Saclay, \\ CentraleSupélec, CNRS, GeePs \\ 91192 Gif sur Yvette, \\ Paris, France \\ khadim.jan@geeps.centralesupelec.fr
}

\author{
Aurore Brézard Oudot \\ Université Paris-Saclay, \\ CentraleSupélec, CNRS, GeePs \\ 91192 Gif sur Yvette, \\ Paris, France \\ aurore.brezardoudot@centralesupelec.fr \\ Demba Diallo \\ Université Paris-Saclay, \\ CentraleSupélec, CNRS, GeePs \\ 91192 Gif sur Yvette, \\ Paris, France \\ demba.diallo@centralesupelec.fr
}

\author{
Anne Migan Dubois \\ Université Paris-Saclay, \\ CentraleSupélec, CNRS, GeePs \\ 91192 Gif sur Yvette, \\ Paris, France \\ anne.dubois@centralesupelec.fr
}

\begin{abstract}
One of the common challenges in remote microgrid installations is inexpensive, reliable, and less laborintensive battery tests to measure the capacity of used batteries and link it to their remaining life. These capacity tests are usually misinterpreted, which results in a healthy battery being junked or may arise economic issues due to oversized battery banks in microgrids. In this work, we conducted several discharge experiments on $12 \mathrm{~V} 100 \mathrm{Ah}$ lead-acid batteries in a controlled manner using an electronic load. The battery is subsequently discharged to $10.5 \mathrm{~V}$ at $\mathrm{C}_{2.5}, \mathrm{C}_{3}, \mathrm{C}_{5}, \mathrm{C}_{10}, \mathrm{C}_{20}$, and $\mathrm{C}_{40}$ rates. When summed up using altered $\mathrm{C}$-rate discharge sequences, the individual capacities resulted in $100.71 \mathrm{Ah}$, $100.23 \mathrm{Ah}$ and $78.96 \mathrm{Ah}, 89.43 \mathrm{Ah}$ for the fresh and weak batteries, respectively. Irrespective of the discharge sequence, the cumulative net capacities are found quite close to the battery's actual capacity for fresh but much different for weak batteries. Results show that the remaining battery's true capacity does not disappear at a high rate and may further be utilized at lower discharge rates. The outcome of these experiments provides the basis to identify fresh and weak batteries and to size the battery banks for the low-cost rural microgrids more efficiently and economically.
\end{abstract}

Keywords-Peukert's law, second-life battery, battery capacity, microgrid, capacity measurement.

\section{INTRODUCTION}

The lead-acid batteries hold a significant leading position in the microgrid market. Energy storage in batteries had remained an increasingly critical asset in many systems, including the starting/lighting/ignition (SLI) in vehicles [1, 2], renewable systems, electric traction, and the most trending one-off-grid electrification, as reported in the Global Energy Storage Database (DOE) report in 2018 [3, 4]. The proven versatility and low cost enabled this technology to use over a hundred years for storing electrical energy [5]. The basic chemistry of the lead-acid batteries is fairly simple [6], but they are complicated, especially when it comes to the capacity response to various loads and different operational situations [7-9]. The degradation mechanisms in batteries are complex, and a detailed analytical description of electrochemical processes involved for the determination of the residual capacity is not explicitly available [10]. Due to the complicated nature of the batteries, most often, the batteries are replaced before their diminished capacities, or on the other hand, the battery bank is incorrectly designed that eventually

This research is fully funded by the Islamic Development Bank (IsDB) under Agreement No. 600036563 Sustainable Energy \& Power. *As a faculty member of the Department of Electrical Engineering, full support is received from the University of Engineering \& Technology, 23200, Mardan, Khyber Pakhtunkhwa, Pakistan. result in failure of the target application of which the most affected is the off-grid renewable or hybrid renewable electrification systems [11].

In applications like off-grid electrification systems, apart from the popular flooded lead-acid batteries, another attractive option is valve-regulated lead-acid (VRLA) batteries, which are studied in this work - they require low maintenance and are classified as absorbent glass mat (AGM) batteries and gel electrolyte batteries [12]. In addition, VRLA batteries use much less electrolyte than traditional lead-acid batteries, they are also occasionally referred to as an acid-starved design. VRLA batteries can be mounted in any position. These batteries are designed to be recombinant to eliminate the emission of gases during overcharge, thereby reducing room ventilation requirements. Furthermore, little or no acid fumes are emitted during the normal operation of VRLA batteries. In the event of damage to a VRLA battery, the volume of free electrolyte that could be released is quite small. Finally, there is no need to check electrolyte levels or add water which is lost due to electrolysis. Thus, VRLA batteries are well suited in rural electrification as they are safer, versatile, environment friendly, and require less maintenance [13].

In modern applications, where the remaining battery capacity is crucial, i.e., not only the SLI, but the most critical one-off-grid electrification services; battery users frequently overcharge, inefficiently cycle, and prematurely replace their batteries because accurate and affordable measurement systems for the test and recovery of these batteries do not exist. As a battery gets older, its usable capacity does not fall off in a cliff-like manner, but instead tends to slowly decrease, which is also recoverable. In areas with an increased power cut or no access to electricity, such poor management of batteries and early replacement increases financial stress on the poor and, in parallel, reduces their trust in such stand-alone community microgrids.

Generally, battery state of charge (SOC) is measured by various battery testing equipment, battery management systems (BMS), and software tools to determine the health of a battery $[14,15]$. However, testing SOC does not give an accurate measure of a battery's health or remaining capacity [16]. The key measurement of remaining battery life is the percentage of original design capacity or the residual capacity determined by a series of discharge tests at different C-rates. The better way to test capacity is using a constant DC current 
sink such as an electronic load for a certain amount of time. However, the constant current sink method is misunderstood and the obtained results are never realistic to reflect the true residual capacity. More than that, most often, the capacity measurement tests are carried out without considering the recovery and loss of battery capacity due to self-discharge, off-service status, and battery relaxation and thermal equilibrium of electrolyte [17].

\section{Paper contribution}

In almost all applications, as stated before - the battery bank stays off-service due to one or other reason and the battery itself is left discharged for a couple of days or an indefinite time. Therefore, our proposed repeated discharge tests at different $\mathrm{C}$-rates and altered sequences enable us to accurately calculate the actual remaining capacity in a supervised manner. Also, it helps to mark/ sort the fresh and weak batteries based on the accumulated individual capacity measurements.

The remaining paper is organized as follows. Section II covers the capacity response and the use of Peukert's equation. In Section III, experimental setup and procedures have been carried out to calculate the battery's actual residual capacity and clarify the confusion created by misinterpretations of Peukert's equation. The measurements and results are discussed with more details in Section IV. Finally, in Section $\mathrm{V}$, conclusions are drawn and some perspectives are given for the possible future experimental outcomes.

\section{PEUKERT'S EQUATION AND CAPACITY RESPONSE OF A BATTERY AT HIGH DISCHARGE}

The misinterpreted Peukert's law was initially developed for lead-acid batteries over a hundred years ago [18]. This law states that the delivered charge increases when the discharge current decreases or conversely, the battery capacity decreases with an increase in discharge current. In fact, the battery's capacity does not depend on how quickly it is being discharged or charged. The battery datasheet provided by the manufacturers is a piece of useful information. At some point, the datasheets are used incorrectly and mainly misunderstood, especially for the battery capacity.

The concept behind Peukert's equation is widely available in the prior art [19]. It came about over a millennium back in 1897 from a German scientist named-Wilhelm Peukert. Peukert realized that the behavior of storage batteries is complicated to understand. There are no good models even today to understand how a battery behaves in all. In fact, there is no general model that is correct for capacity determination. With many complications, even today, the battery models that exist; most of these are the computer models, as they are specifically tailored for one specific application and technology.

Peukert's law expresses the capacity of a battery in terms of the rate at which it is discharged. It is described as the following equation:

$$
C_{N}=I^{k} * t(k>1)
$$

where, $C_{N}$ is the nominal capacity of the battery, $I$ is the discharge current, $k$ is the Peukert's constant, which is determined by the internal characteristics of the batteries and its value is greater than one, and $t$ is the discharge time. The equation indicates that the discharge time and battery capacity decrease exponentially at any given nominal capacity $C_{N}$ as the discharge current is increased. In addition, the discharge capacity $C_{D}$ is described in (2) by using the same notation as in (1):

$$
C_{D}=I * t=I^{(1-k)} * C_{N}(\mathrm{k}>1)
$$

Equation (2) indicates that excessive $I$ causes a reduction in the discharge capacity. However, it is shown experimentally that the capacity does not disappear with a high discharge current for fresh but significantly lost for used batteries.

Peukert was able to go through some empirical testing with battery technology and computing tools of that time. He demonstrated that if a battery is charged very quickly, much useful capacity cannot be obtained during discharge. If the same battery is discharged very slowly, far more useful energy out of the battery can be extracted. This complex discharge behavior of batteries is usually misinterpreted for sizing storage batteries in microgrids. This has many practical implications and, in parallel, a lot more confusion. Interestingly, Peukert did a very good job. His data set had remained quite useful, but sometimes not used in its true sense for the capacity response of a battery.

The battery datasheet is misunderstood when the discharge capacity is confused with the battery's true capacity. The datasheet of the battery used in this work [20] claims that the amp-hour (Ah) capacity depends on the discharge rate, but as we demonstrate, this capacity is just the useful capacity. If the battery is continuously discharged at the ten-hour rate $\left(\mathrm{C}_{10}\right)$ with a constant DC load current of $10 \mathrm{~A}$, the battery will drop to a voltage, i.e., $10.5 \mathrm{~V}$, which is deemed not useful for further discharge. If the 100Ah battery is discharged very quickly, say at a five-hour rate $\left(\mathrm{C}_{5}\right)$ with $20 \mathrm{~A}$, it will drop to that minimum acceptable voltage much quicker. However, this does not mean that the capacity went away at $\mathrm{C}_{5}$, it means that the remaining capacity is no more useful at $\mathrm{C}_{5}$. The remaining capacity can still be used at a lower discharge rate and more out of the Ah can be extracted from the battery.

\section{EXPERIMENTAL SETUP AND METHODS}

The batteries used in this demonstration are $12 \mathrm{~V} 100 \mathrm{Ah}$ Ultracell ${ }^{\circledR}$ UCG 100-12 lead-gel technology. The system setup is as shown in Fig. 1. It consists of a ZS-1812 H\&H DC electronic load, lead-acid battery, and a supervisor PC to discharge batteries in a controlled manner. The interface NI6009 is used between the supervisor PC and electronic load.

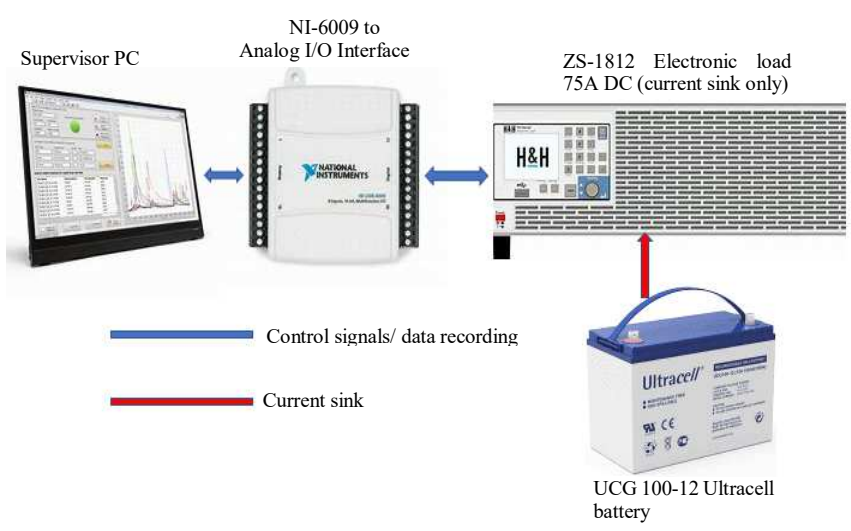

Fig. 1. Schematic representation of the experimental platform for the capacity determination using successive discharges 
All the batteries under test are 100Ah each, weigh 67 pounds, and are of AGM gel electrolyte F10 terminal construction [18]. Before starting the discharge tests, batteries are fully charged using H-Tronic HTDC 5000 (5A) smart charger. In the first test, a single $12 \mathrm{~V}$ battery is randomly selected among the bank of 16 batteries. The lower discharge threshold is set to $10.50 \mathrm{~V}(1.75 \mathrm{~V} /$ cell $)$.

\section{A. Experimental Procedure}

The whole experimental bench is depicted in Fig. 2. In this figure, the electronic load is connected to the supervisor PC via NI6009 to Analog I/O interface to run the experiment in a controlled manner. The cables are of sufficient gauge and minimal length to minimize the voltage drop during high discharge currents. It was observed that these cables survived during the high discharge current test, and they did not heat up abnormally. However, the cable selection could be different for other equipment and may better be adapted to as per application.

The electronic load is initialized and configured to the external mode using LabVIEW $^{\circledR}$ to observe the battery's behavior at different C-rates. This interface is also used to send control signals and measure the battery voltage and current. As shown in the flow diagram of Fig. 3, the discharge process is repeated for other $\mathrm{C}$-rates until $\mathrm{C}_{40}(2.5 \mathrm{~A})$. Onehour relaxation time is used for the open-circuit voltage (OCV) recovery and thermal equilibrium of electrolyte. The total discharge time is recorded each time and multiplied with the discharge current to get the extracted capacity in Ah. After the test is finished for a sequence, the battery is fully recharged to pass through another discharge using a different sequence. Important control parameters and different thresholds for the experiment are detailed in Table I.

TABLE I: ZS1812 CONTROL PARAMETERS AND SETTINGS

\begin{tabular}{c|c|c|c|c}
\hline Load type & $\begin{array}{c}\text { Range/ } \\
\text { Resolution }\end{array}$ & Interface & Mode & Accuracy \\
\hline $\begin{array}{c}\text { ZS-1812 } \\
\text { current sink }\end{array}$ & $\begin{array}{c}75 \mathrm{~A} \text { DC / } \\
\text { R2 settings }\end{array}$ & $\begin{array}{c}\text { NI-6009 to } \\
\text { Analog I/O }\end{array}$ & $\begin{array}{c}\text { CC const. } \\
\text { current }\end{array}$ & $\begin{array}{c} \pm 0.2 \% \text { of } \\
\text { measured value }\end{array}$ \\
\hline Supervisor & $\begin{array}{c}\text { Control } \\
\text { mode }\end{array}$ & $\begin{array}{c}\text { Battery } \\
\text { type }\end{array}$ & $\begin{array}{c}\text { Cut-off } \\
\text { threshold }\end{array}$ & $\begin{array}{c}\text { Relaxation/ } \\
\text { Recovery time }\end{array}$ \\
\hline $\begin{array}{c}\text { LabVIEW } \\
2013\end{array}$ & $\begin{array}{c}\text { External } \\
\text { mode }\end{array}$ & $\begin{array}{c}\text { UCG-100/ } \\
12 \text { lead-gel }\end{array}$ & $10.50 \mathrm{~V}$ & 60 mins \\
\hline Charger & $\begin{array}{c}\text { Fully } \\
\text { charge volt }\end{array}$ & Temp. & $\begin{array}{c}\text { Capacity } \\
\text { C=C }\end{array}$ & $\begin{array}{c}\text { Discharge } \\
\text { Sequences }\end{array}$ \\
\hline $\begin{array}{c}\text { H-Tronic } \\
\text { HTDC5000 }\end{array}$ & $14.30 \mathrm{~V}$ & Ambient & $100 \mathrm{Ah}$ & 2
\end{tabular}

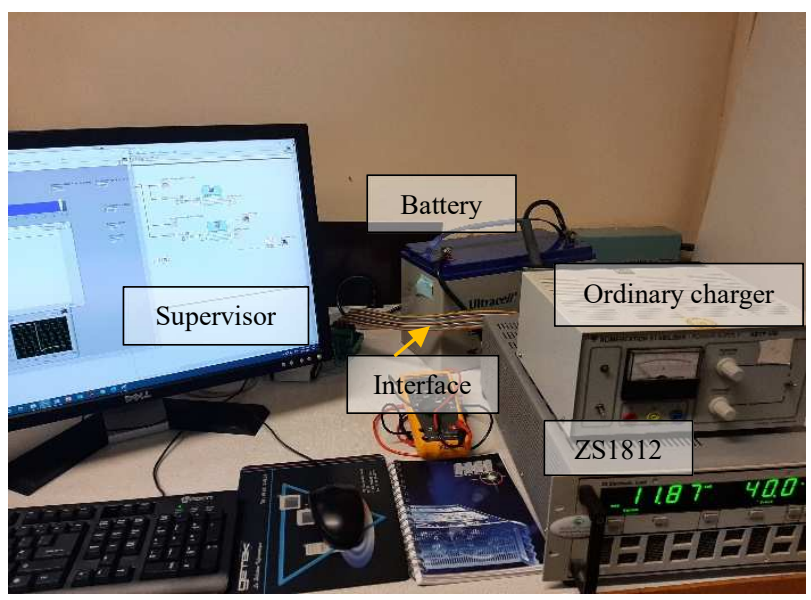

Fig. 2. Experimental bench for the net capacity calculation in a controlled manner

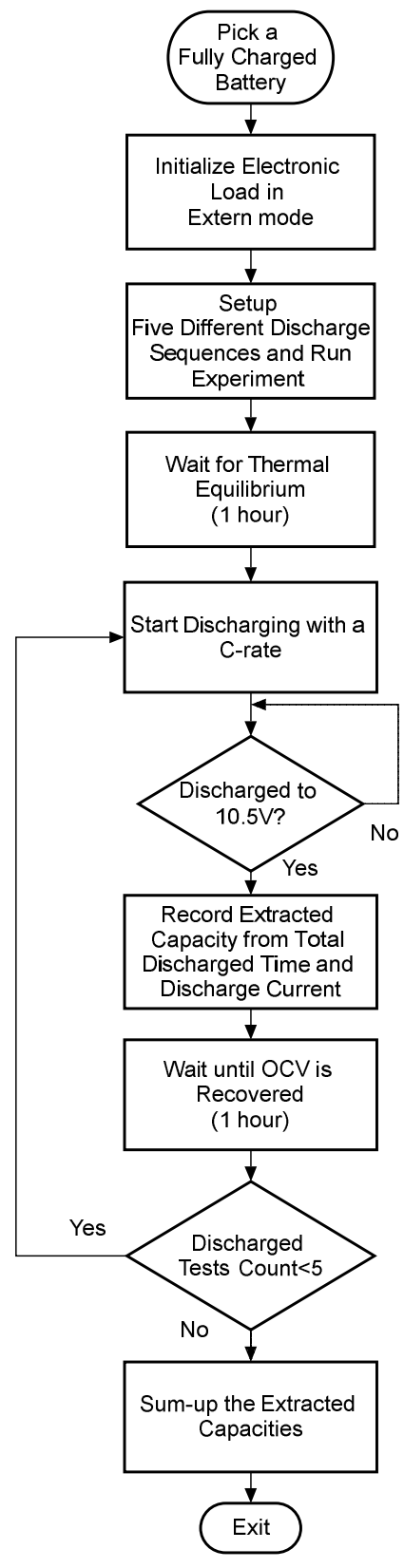

Fig. 3. Flow diagram of the experimental process

\section{B. Discharge Sequences}

The following C-rates are used in a shuffled sequence to extract the residual capacity of a fully charged battery:

$$
\begin{array}{llllll}
\mathrm{C}_{2.5} & \mathrm{C}_{5} & \mathrm{C}_{10} & \mathrm{C}_{20} & \mathrm{C}_{40} & \text { (fresh battery) } \\
\mathrm{C}_{3} & \mathrm{C}_{5} & \mathrm{C}_{20} & \mathrm{C}_{10} & \mathrm{C}_{40} & \text { (weak battery) }
\end{array}
$$

where $\mathrm{C}$ is the rated capacity of the battery under test, which is $100 \mathrm{Ah}$ at $\mathrm{C}_{10}$. The discharge currents are configured in LabVIEW $^{\circledR}$ and sent to ZS-1812 electronic load using NI6009 . At the $\mathrm{R}_{2}$ resolution settings (configured via port 0 ) with a bit sequence of 00000100 , the following voltage ranges are fed to the control of different discharge currents:
$\mathrm{C}_{2.5}$
$\mathrm{C}_{3}$
$\mathrm{C}_{5}$
$\mathrm{C}_{10}$
$\mathrm{C}_{20}$
$\mathrm{C}_{40}$
(2V)
$(1.67 \mathrm{~V})$
$(1 \mathrm{~V})$
$(0.5 \mathrm{~V})$
$(0.25 \mathrm{~V})$

The electronic load is easily disconnected from the battery through a TTL signal at P1.0 (disconnect HIGH). Altering the 
discharge sequence enabled the authors to identify fresh and weak batteries based on the net extracted capacity. The fresh battery has no significant capacity loss with a high discharge current. However, the capacity of a weak battery is affected by a high discharge current.

\section{MEAsurements AND DATA RECORDING}

In our case, a fully charged $12 \mathrm{~V}$ lead-acid battery is drained to the cut-off threshold of $10.5 \mathrm{~V}$, and still, the remaining capacity turned useful on successive low discharge currents. It is an indication that this capacity calculation method using repeated discharges and different $\mathrm{C}$-rates could help calculate the overall remaining capacity of the battery. The discharge process was carefully controlled to avoid the battery getting sulfated or being damaged from deep discharge using set threshold of $10.5 \mathrm{~V}$ at the ambient room temperature. As depicted in Table II, we got 100.7Ah and 100.2Ah during the two different discharge sequences for fresh batteries. These results are quite close to the battery's rated capacity. It is observed that altering the discharge sequence did not affect the fresh battery but affected the weak battery.

Out of the 16 batteries on-site, few were identified as weak batteries based on the obtained results (89.4Ah to 78.9Ah) by altering the discharge sequence. The high discharge current roughly dropped $10 \mathrm{Ah}$ of the useful capacity for the weak battery. It is a result of internal capacity loss due to high plate resistance and degradation.

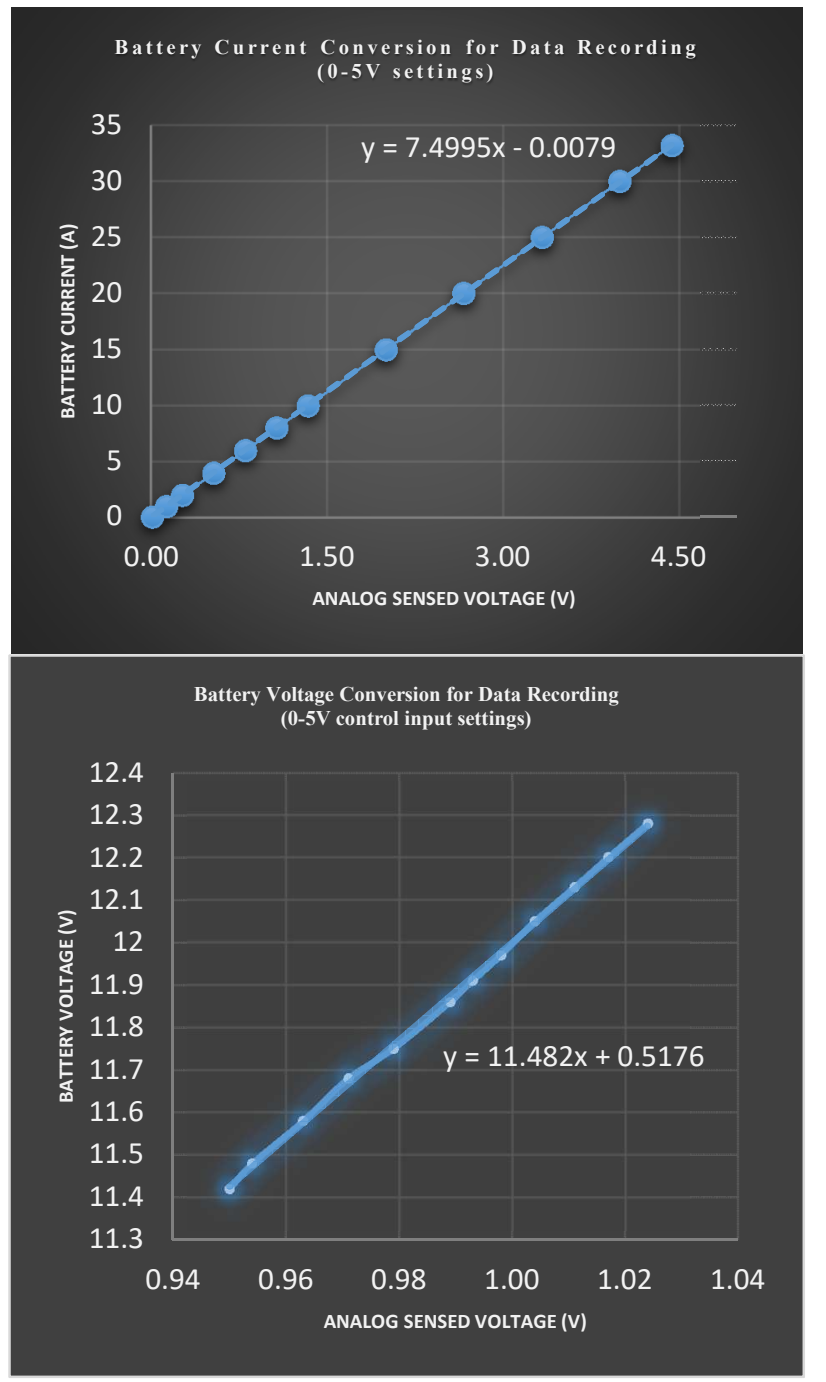

Fig. 4. ZS1812 electronic load settings: Data recording and linear conversion (from ZS1812 to LabVIEW ${ }^{\circledR}$ )
TABLE II: IDENTIFICATION OF FRESH AND WEAK BATTERIES

\begin{tabular}{|c|c|c|c|c|c|c|c|c|c|}
\hline \multicolumn{5}{|c|}{ Battery A (fresh) } & \multicolumn{5}{|c|}{ Battery B (weak) } \\
\hline \multicolumn{10}{|c|}{$\begin{array}{l}\text { Discharge sequence (Test-1) } \\
\qquad \mathrm{C}=\mathrm{C}_{10}=100 \mathrm{Ah}\end{array}$} \\
\hline $\mathrm{C}_{3}$ & $\mathrm{C}_{5}$ & $\mathrm{C}_{10}$ & $\mathrm{C}_{20}$ & $\mathrm{C}_{40}$ & $\mathrm{C}_{3}$ & $\mathrm{C}_{5}$ & $\mathrm{C}_{20}$ & $\mathrm{C}_{10}$ & $\mathrm{C}_{40}$ \\
\hline 83.2 & 6.6 & 5.0 & 2.9 & 2.4 & 66.6 & 9.3 & 8.9 & 0.8 & 3.7 \\
\hline \multicolumn{5}{|c|}{$\begin{array}{c}\text { 100.2Ah } \\
\text { (Total extracted capacity) }\end{array}$} & \multicolumn{5}{|c|}{$\begin{array}{l}\text { 89.4Ah } \\
\text { extracted capacity) }\end{array}$} \\
\hline \multicolumn{10}{|c|}{$\begin{array}{l}\text { Altered discharge sequence (Test-2) } \\
\qquad \mathrm{C}=\mathrm{C}_{10}=100 \mathrm{Ah}\end{array}$} \\
\hline $\mathrm{C}_{2.5}$ & $\mathrm{C}_{5}$ & $\mathrm{C}_{10}$ & $\mathrm{C}_{20}$ & $\mathrm{C}_{40}$ & $\mathrm{C}_{2.5}$ & $\mathrm{C}_{2.5}$ & $\mathrm{C}_{10}$ & $\mathrm{C}_{20}$ & $\mathrm{C}_{40}$ \\
\hline 74.6 & 11.3 & 6.0 & 4.1 & 4.6 & 64.6 & 4.6 & 5.5 & 2.2 & 1.8 \\
\hline \multicolumn{5}{|c|}{$\begin{array}{c}\text { 100.7Ah } \\
\text { (Total extracted capacity) }\end{array}$} & \multicolumn{5}{|c|}{$\begin{array}{c}\text { 78.9Ah } \\
\text { (Total extracted capacity) }\end{array}$} \\
\hline \multicolumn{5}{|c|}{ Negligible capacity loss } & \multicolumn{5}{|c|}{$\begin{array}{c}\text { High capacity loss } \\
\text { (due to internal plate resistance) }\end{array}$} \\
\hline
\end{tabular}

The obtained results for the different discharge sequences and different batteries are compared in Table II and graphically represented using Fig. 5. It is interesting to note that the extracted capacities for the weak batteries have a significant deviation due to the altered discharge sequence. It indicates aging and capacity loss due to an increase in the internal plate resistance. We have demonstrated with a real practical battery that the battery does not lose its residual capacity at high $\mathrm{C}$-rates as is being misinterpreted. The response in Fig.6, when summed up, the individual capacities resulted quite nearly to the rated Ah capacity of the fresh battery as the internal loss is quite low and the impact of altered sequence is negligible.
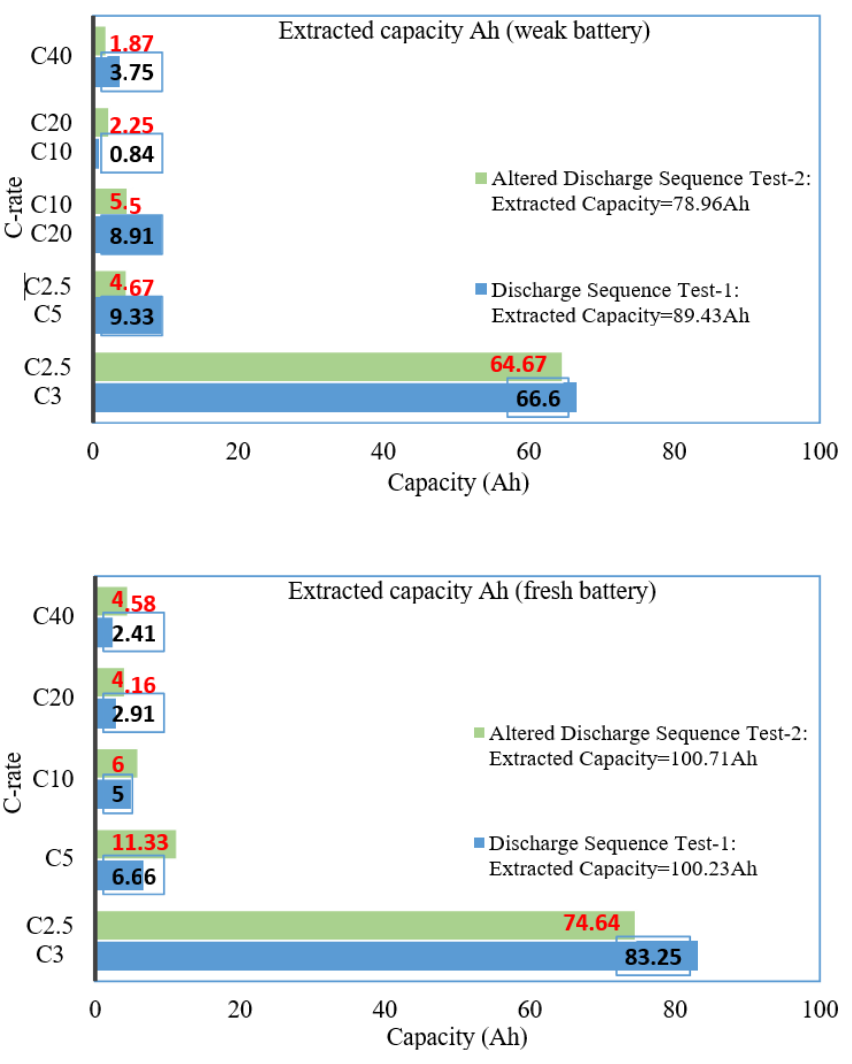

Fig. 5. Extracted capacities from a fully charged $12 \mathrm{~V}$ battery with different health status (weak/fresh) 
The adequate experimental validation in this work shows that a battery does not lose much capacity by discharging it at a high current. It is obvious from the obtained results that the batteries could still be utilized in different groups with different discharge current sequences to take out the maximum of their true capacities and serve longer. These experiments could be of particular interest for the selection of batteries in low-cost stand-alone microgrids.

\section{CONCLUSION}

The experimental validations on real batteries using successive discharge had reliably determined the remaining true capacity of lead-acid batteries. It was practically demonstrated that a certain battery, e.g., 100Ah AGM in our case, was discharged five times to the threshold of $10.5 \mathrm{~V}$ with an hour relaxation for voltage recovery and thermal equilibrium of electrolyte. It is observed that irrespective of the C-rates, the net extracted capacities 100.71 Ah, 100.23Ah matched exactly the datasheet values for fresh batteries but found a quite large deviation of 78.96Ah, 89.43 Ah for weak batteries. The overall analysis also enabled the authors to quickly sort the second-life batteries in fresh and weak groups for use as a battery pack of different health status in reducing the storage cost of off-grid electrification systems for the rural areas. For future work, an extension of these experiments could be used for the parameter extraction of real batteries. This could be helpful in adaptive tuning of the energy management system to evolve with the degraded performance of aged batteries, and also health monitoring of the batteries.

\section{ACKNOWLEDGMENT}

Discussion with several colleagues was valuable in clarifying some of the thoughts given here, for which we are grateful. The authors would also like to thank Eric Labouré, Eric, B. and Richard, A. for the experimental bench setup, Olivier, H. and Anthony, G. for the IT support, and Islamic Development Bank (IsDB) for the funding.

\section{REFERENCES}

[1] M. J. Lencwe, S. P. Daniel Chowdhury, and T. O. Olwal, "Performance studies of lead acid batteries for transport vehicles," 2017 IEEE PES PowerAfrica Conference, pp. 528-532, 2017.

[2] M. Ceraolo, T. Huria, G. Pede, and F. Vellucci, "Lithium-ion startinglighting-ignition batteries: Examining the feasibility," in Proceedings of Vehicle Power and Propulsion Conference (VPPC'2011), pp. 1-6, 10.1109/VPPC.2011.6043116, Oct. 2011.

[3] The DOE Global Energy Storage Database, 2019. [Online], Available: Accessd On January 16, 2020. http://www.energystorageexchange.org/ projects/data_visualization.
[4] M. Farhadi, and O. Mohammed, "Energy Storage Technologies for Highpower Applications," IEEE Trans. Ind. Appl., vol. 52, no. 3, pp. 1953-1961, Jun. 2016.

[5] G. L. Plett, "Method for Monitoring Remaining Battery Capacity," US Patent: No. 5,808,445, 1998.

[6] A. J. Salkind, A. G. Cannone, and F. A. Trumbure, "Lead-Acid Batteries", Handbook of batteries, Third Edition, McGraw-Hill, 2001, ISBN 0-07-135978-8.

[7] Power Sonic Technical Literature "Sealed Lead Acid Batteries," [Online], Accessed on January 16, 2020. https://www.powersonic.com/wp-content/uploads/2018/12/Technical-Manual.pdf.

[8] M. B. Pinson and M. Z. Bazant, "Theory of SEI formation in rechargeable batteries: capacity fade, accelerated aging and lifetime prediction," Journal of the Electrochemical Society, vol. 160, no. 2, pp. 243-250, 2013.

[9] D. Linden, "Handbook of Batteries," McGraw Hill, New York, 1995.

[10] M. Hughes et al. "The Residual Capacity Estimation of Fully Sealed 25Ah Lead/Acid Cells," Journal Of Power Sources, Vol. 17, 1986, pp.305-329.

[11] M. Nasir, H. A. Khan, A. Hussain, L. Mateen, and N. A. Zaffar, "Solar PV-Based Scalable DC Microgrid for Rural Electrification in Developing Regions," in IEEE Transactions on Sustainable Energy, vol. 9, no. 1, pp. 390-399, Jan. 2018.

[12] W. Jie, L. Hua, C. Peijie, Q. Deyu, and L. Shan, "Design of Energy Storage System using Retired Valve Regulated Lead Acid (VRLA) Batteries in Substations," in IEEE Conference on Energy Conversion (CENCON'19), pp. 132-136, 2019.

[13] G. J. May, A. Davidson, and B. Monahov, "Lead batteries for utility energy storage: a review," Journal of Energy Storage, vol.15, pp. 145$157,2018$.

[14] IEEE Approved Draft Recommended Practice for Sizing Lead-Acid Batteries for Stand-Alone Photovoltaic (PV) Systems," in IEEE Standards, P1013/D1.3, pp. 1-54, $21^{\text {st }}$ May 2019.

[15] W.Visser, "State of Charge Characteristics of the Lead Acid Battery," Journal of Power Sources, 1985, pp.525-535.

[16] M. A. Roscher, J. Assfalg and O. S. Bohlen, "Detection of Utilizable Capacity Deterioration in Battery Systems," in IEEE Transactions on Vehicular Technology, vol. 60, no. 1, pp. 98-103, Jan. 2011.

[17] Shi, C. Ferone, C. Rao and C. D. Rahn, "Nondestructive forensic pathology of Lead-Acid batteries," 2012 American Control Conference (ACC), pp. 1350-1355, 2012.

[18] W. Peukert, "Über die Abhängigkeit der Kapazität von der Entladestromstärke bei Bleiakkumulatoren", Elektrotechnische Zeitschrift 20 (1897).

[19] D. Doerel, S. A. Sharkh, "A critical review of using the peukert equation for determining the remaining capacity of lead-acid and li-ion batteries", Journal of Power Sources, 155 (2), pp. 39-400, 2006.

[20] Ultracell batteries "UCG-100 12" [Online] Accessed on May 5, 2021. https://ultracell.co.uk/www.ultracell.co.uk/products/ucgbatteries/12v.html.

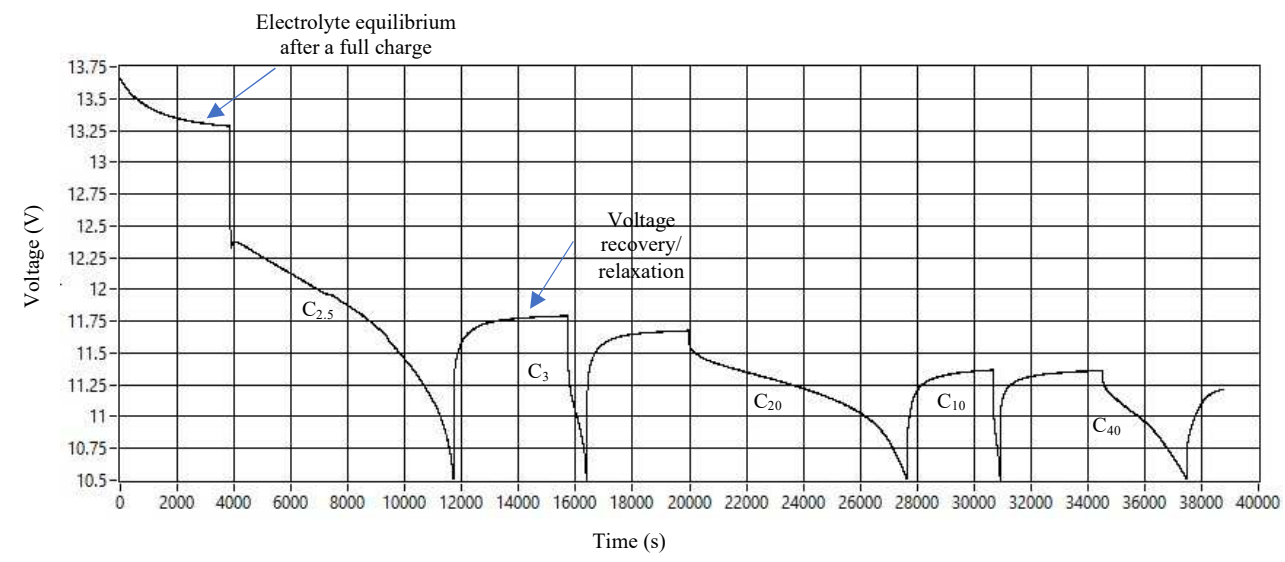

Fig. 6. Net extracted capacity from a fresh battery through five successive discharges 